\title{
NOITES BRANCAS ... OU VÁCUOS TEMPORAIS.
}

\section{Leila Reinert ${ }^{1}$}

A fotografia mostra-se uma valiosa aliada na busca do inesperado, daquilo que nos surpreende no mesmo. A imagem fotográfica, para muito além de ser o registro de um fato, ou a avalista da verdade, é sempre criação/invenção de luz. Espaço/tempo fixado num instante. É do fotográfico decapitar o tempo e embalsamar o instante tornando eterno um lapso.

Apresento uma produção fotográfica cujo o tema são vistas das janelas de lugares por que passei. São fotos noturnas tiradas com longo período de exposição - o diafragma da câmera permanece aberto por muito tempo - de 15 minutos a uma hora, em média. Fotografias analógicas, luz impregnada na película, que leva tempo para ser revelada ao olhar ansioso do fotógrafo.

São fotos que perguntam: qual a duração de um instante? Pois a imagem resultante é ainda aquela de um lapso; de um instante condensado e de um tempo sobreposto no espaço, que satura a paisagem antes mesmo de saturar a imagem. Qual o resíduo de memória do olhar distraído do fotografo, não pela multiplicidade do entorno, mas pela pouca capacidade de concentração? As luzes se apagam, os carros passam, a chuva cai, e o olho não dura 15 minutos, uma hora, ou mais, no quadro da cena proposta. As coisas acontecem e nem olho nem câmera captam a velocidade do lapso. Resta, na imagem, o vazio do tempo que passa sem sentido.

Qual a cidade que se apresenta ao olhar no tempo da espera, do silêncio, da distração? Tempo da fila no banco, do consultório médico, tempo vazio, que esvazia a paisagem antes mesmo de esvaziar a imagem.

\footnotetext{
${ }^{1}$ Universidade Presbiteriana Mackenzie, Brasil.
} 


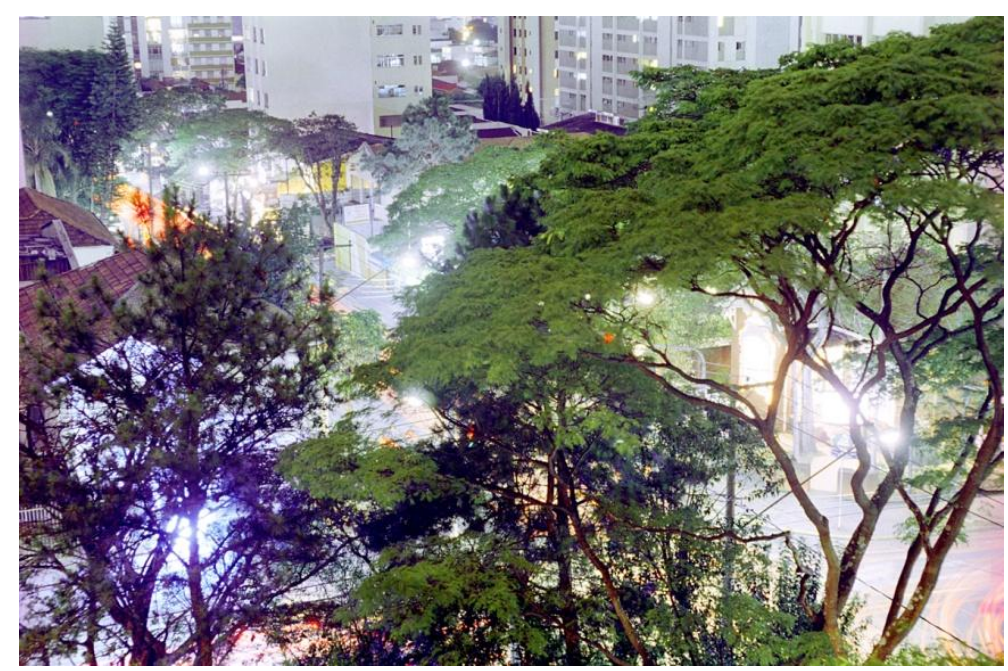

Figura 1 - São Paulo

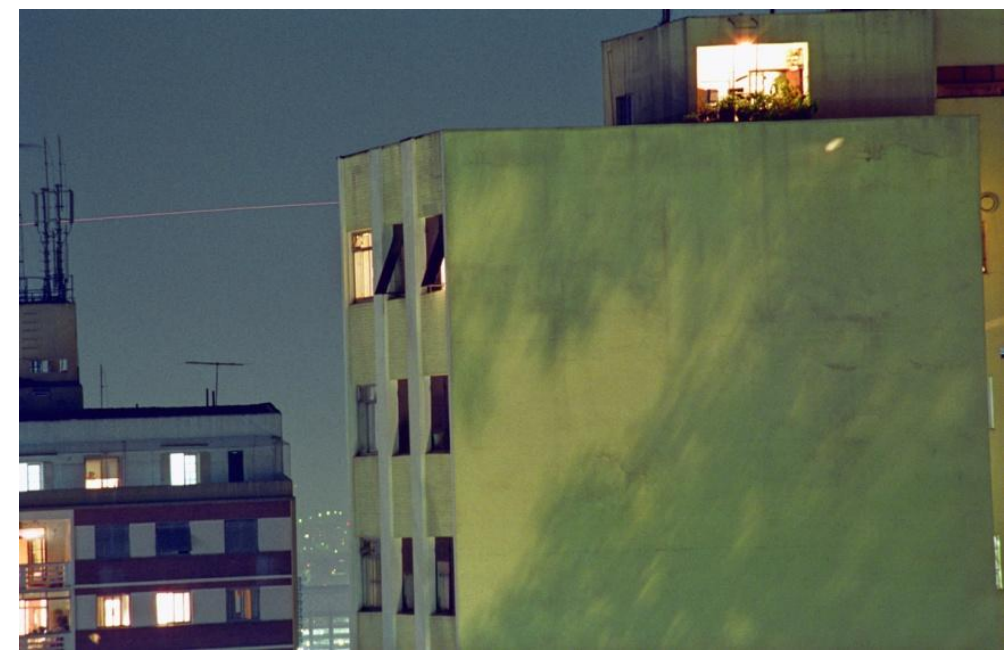

Figura 2 - São Paulo

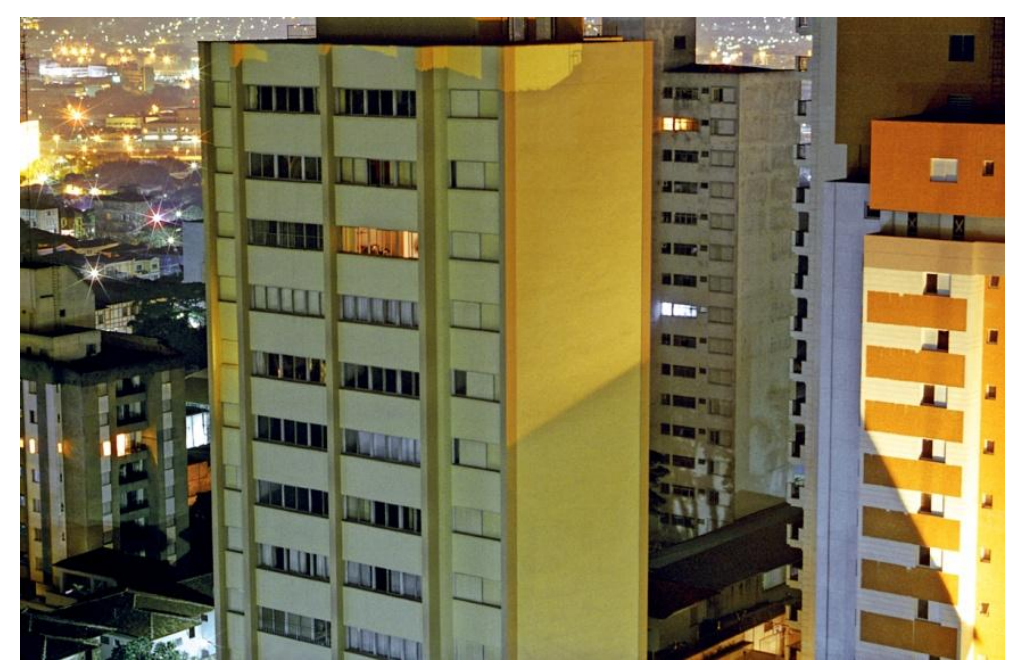

Figura 3 - São Paulo 


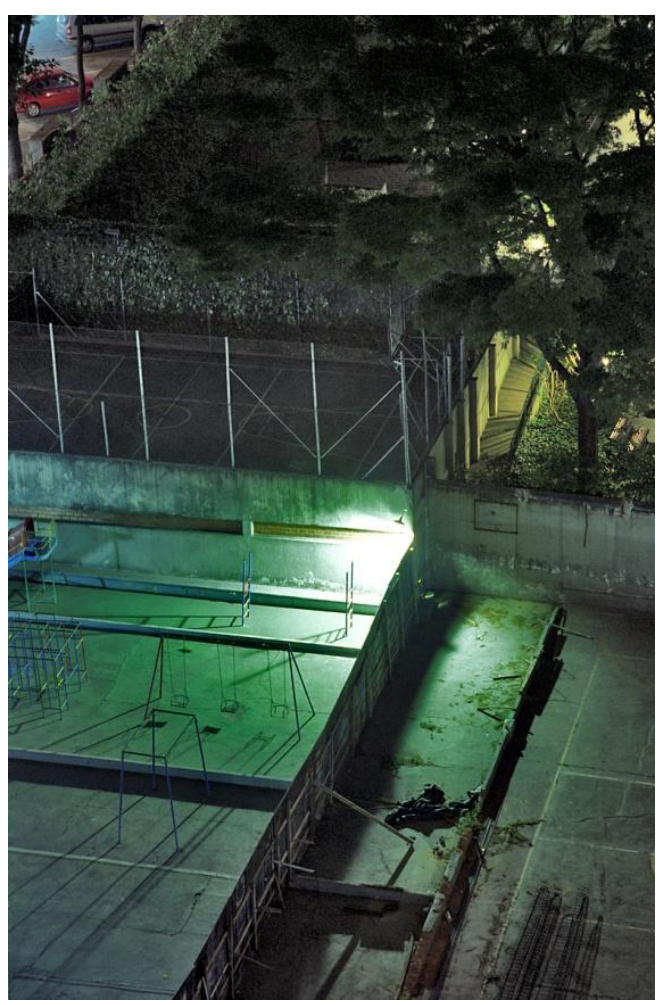

Figura 4 - São Paulo

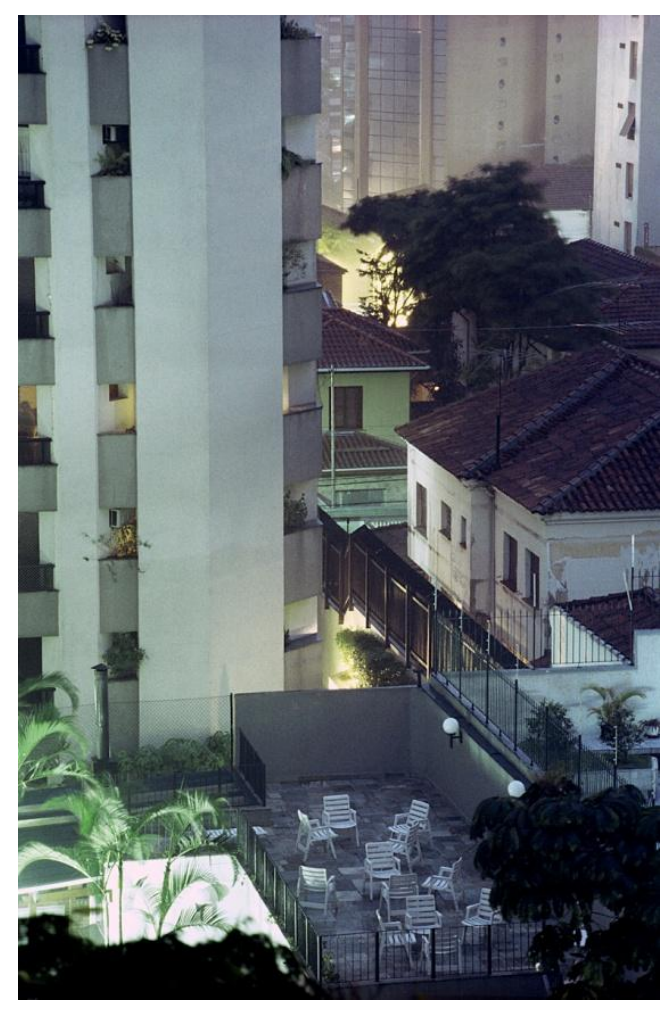

Figura 6 - São Paulo

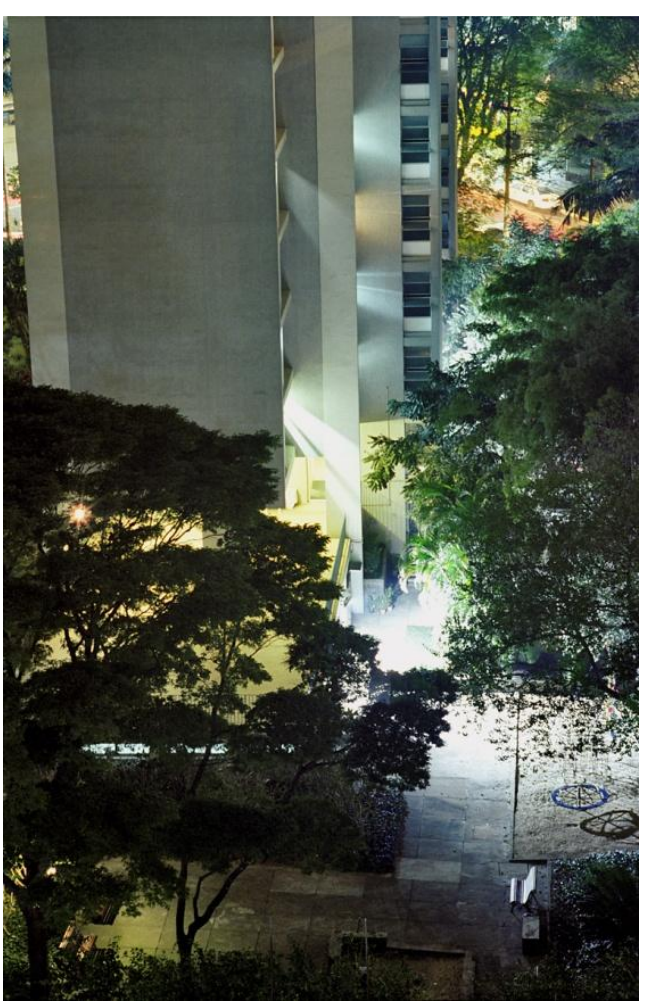

Figura 5 - São Paulo

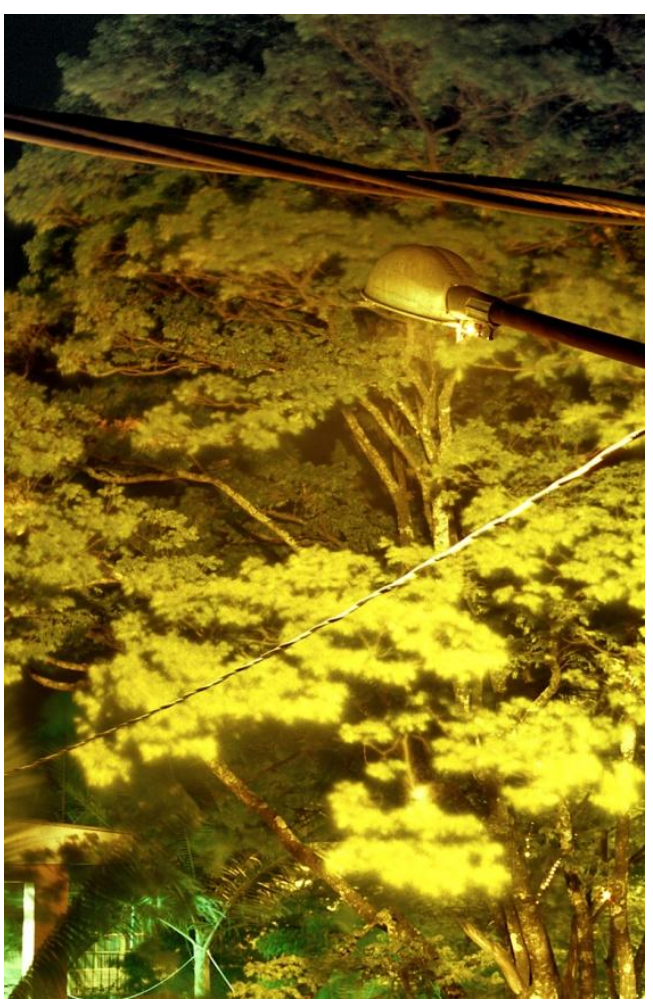

Figura 7 - Extrema 


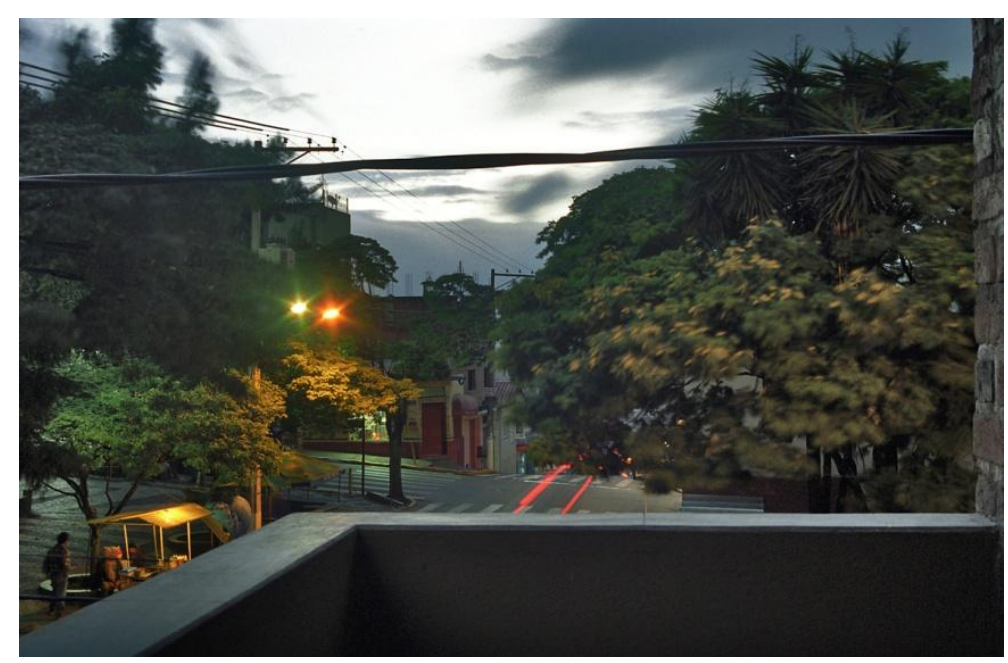

Figura 8 - Extrema

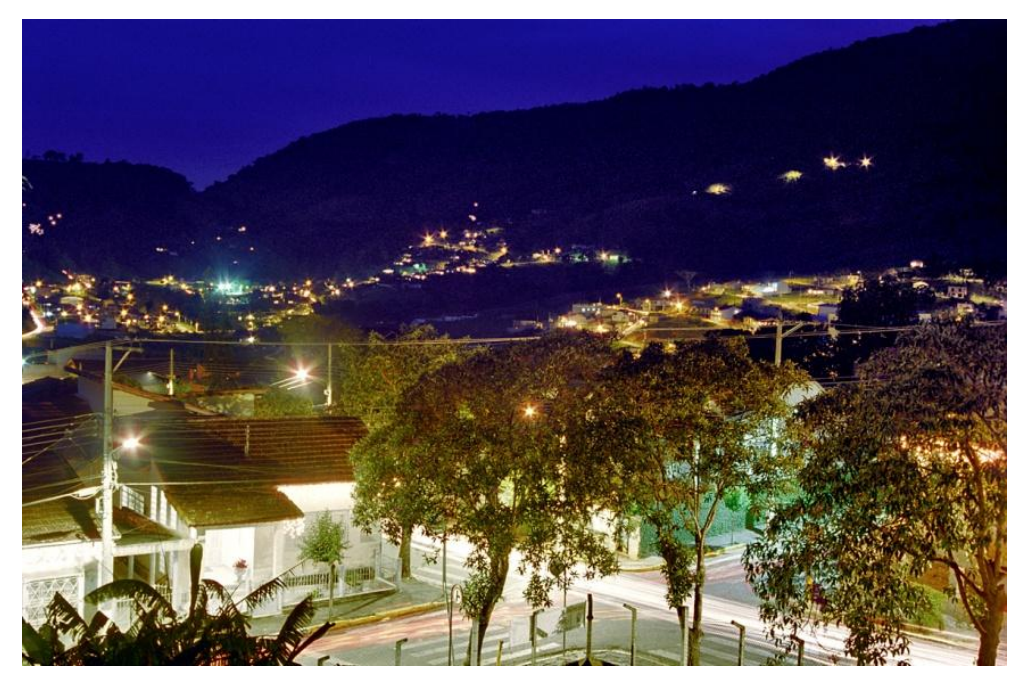

Figura 9 - Extrema

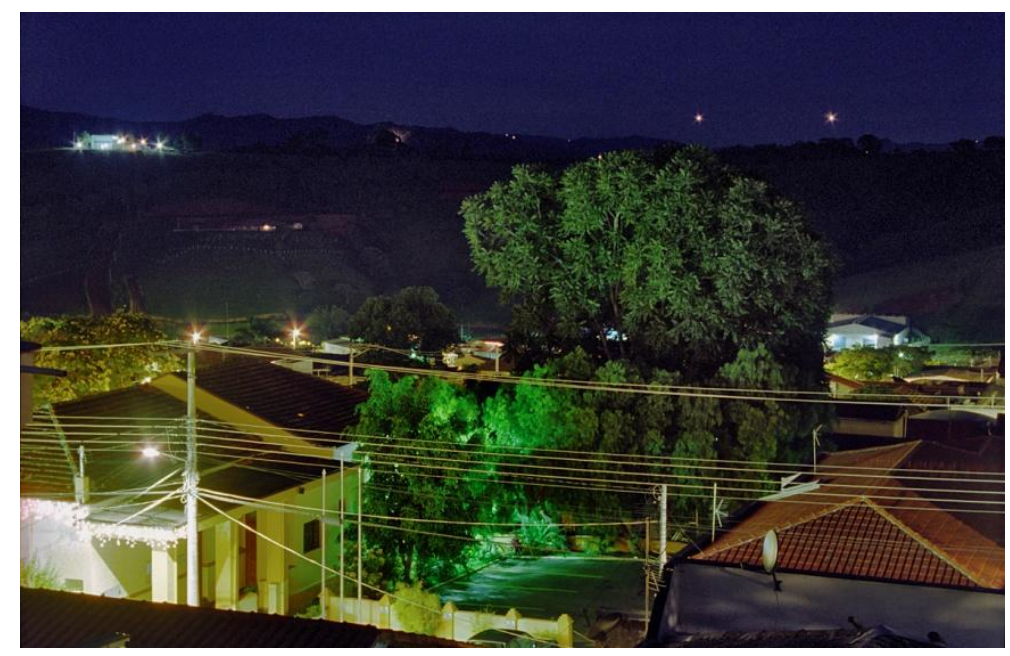

Figura 10 - Extrema 


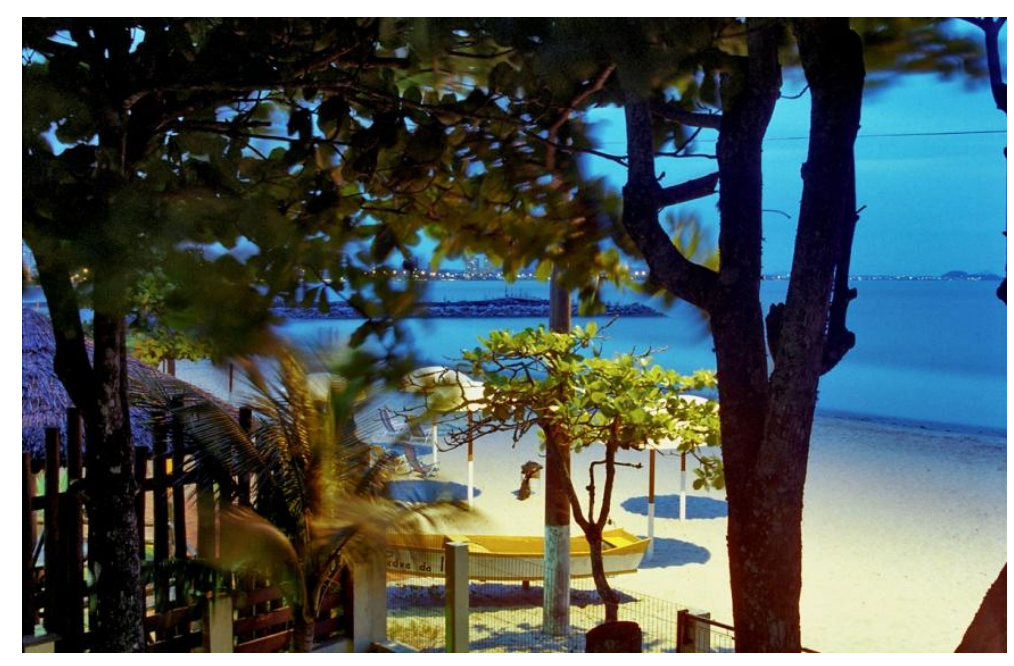

Figura 11 - Praia Alegre

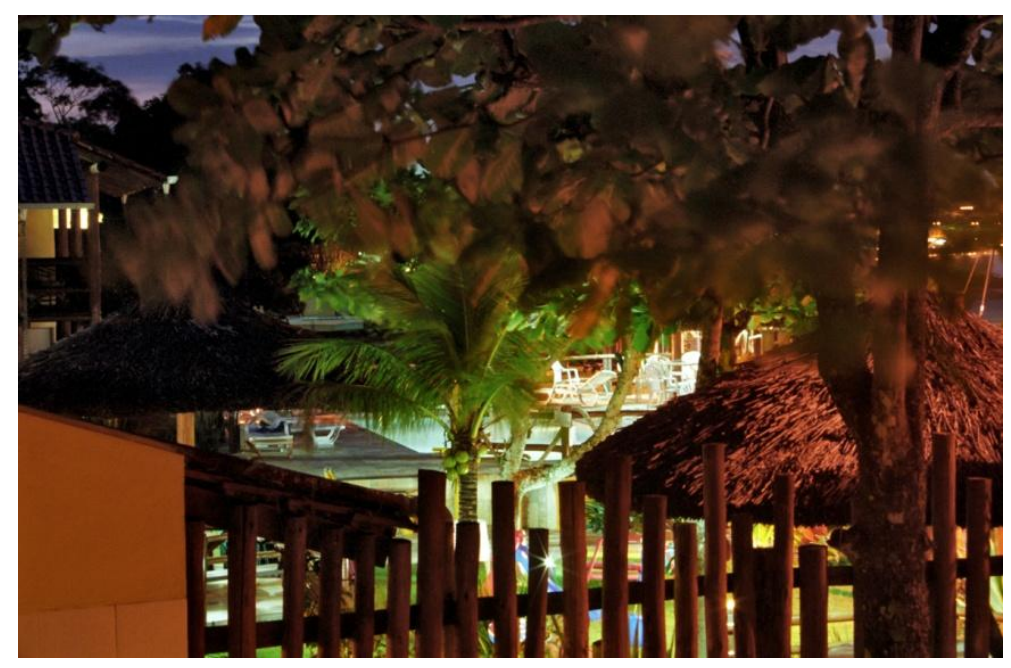

Figura 12 - Praia Alegre 